\title{
Human SAP18 mediates assembly of a splicing regulatory multiprotein complex via its ubiquitin-like fold
}

\author{
KUSUM K. SINGH, ${ }^{1,2,7}$ STEFFEN ERKELENZ, ${ }^{3,7}$ STEPHANIE RATTAY, ${ }^{3}$ ANNA KATHARINA DEHOF, ${ }^{4}$ \\ ANDREAS HILDEBRANDT, ${ }^{4}$ KLAUS SCHULZE-OSTHOFF, ${ }^{1,5,8}$ HEINER SCHAAL, ${ }^{3,8}$ \\ and CHRISTIAN SCHWERK ${ }^{1,6,8}$ \\ ${ }^{1}$ Institute of Molecular Medicine, University of Düsseldorf, D-40225 Düsseldorf, Germany \\ ${ }^{2}$ Institute of Biochemistry and Molecular Biology, RWTH Aachen University, D-52074 Aachen, Germany \\ ${ }^{3}$ Institute for Virology, University of Düsseldorf, D-40225 Düsseldorf, Germany \\ ${ }^{4}$ Center for Bioinformatics, Saarland University, D-66041 Saarbrücken, Germany \\ ${ }^{5}$ Interfaculty Institute for Biochemistry, University of Tübingen, D-72076 Tübingen, Germany \\ ${ }^{6}$ Children's Hospital, Mannheim Medical Faculty, Heidelberg University, Mannheim D-68167, Germany
}

\begin{abstract}
RNPS1, Acinus, and SAP18 form the apoptosis- and splicing-associated protein (ASAP) complex, which is also part of the exon junction complex. Whereas RNPS1 was originally identified as a general activator of mRNA processing, all three proteins have been found within functional spliceosomes. Both RNPS1 and Acinus contain typical motifs of splicing regulatory proteins including arginine/serine-rich domains. Due to the absence of such structural features, however, a function of SAP18 in splicing regulation is completely unknown. Here we have investigated splicing regulatory activities of the ASAP components. Whereas a full-length Acinus isoform displayed only limited splicing regulatory activity, both RNPS1 and, surprisingly, SAP18 strongly modulated splicing regulation. Detailed mutational analysis and three-dimensional modeling data revealed that the ubiquitinlike fold of SAP18 was required for efficient splicing regulatory activity. Coimmunoprecipitation and immunofluorescence experiments demonstrated that SAP18 assembles a nuclear speckle-localized splicing regulatory multiprotein complex including RNPS1 and Acinus via its ubiquitin-like fold. Our results therefore suggest a novel function of SAP18 in splicing regulation.
\end{abstract}

Keywords: SAP18; RNPS1; Acinus; splicing; ubiquitin-like fold

\section{INTRODUCTION}

Splicing of precursor messenger RNAs (pre-mRNAs) describes removal of intervening sequences (introns) and joining of exons. Excision and splicing are performed by the spliceosome, a huge and dynamic multicomponent machinery (Brow 2002; Will and Lührmann 2006). The phenomenon of alternative pre-mRNA splicing allows the generation of multiple transcript isoforms from a common precursor via regulation of splice site selection. Alternative

\footnotetext{
${ }^{7}$ These authors contributed equally to this work.

${ }^{8}$ These authors share senior authorship.

Reprint requests to: Heiner Schaal, Institute for Virology, University of Düsseldorf, Universitätsstrasse 1, Düsseldorf D-40225, Germany; e-mail: schaal@uni-duesseldorf.de; fax: +49 (0)211-81-10856; or Christian Schwerk, Children's Hospital, Mannheim Medical Faculty, University of Heidelberg, Theodor-Kutzer-Ufer 1-3, Mannheim D-68167, Germany; e-mail: christian.schwerk@medma.uni-heidelberg.de; fax: +49 (0)621-3833818.

Article published online ahead of print. Article and publication date are at http://www.rnajournal.org/cgi/doi/10.1261/rna.2304410.
}

splicing plays important roles during regulation of several cellular processes such as sex determination, axon guidance, cell excitation and contraction as well as apoptosis (Maniatis and Tasic 2002; Black 2003; Schwerk and Schulze-Osthoff 2005). Selection of splice sites is a highly complex process, which involves, besides the basal splicing machinery, several regulatory proteins acting in trans with splicing enhancing, silencing, or even both regulatory activities. Whereas members of the heterogeneous nuclear ribonucleoproteins (hnRNPs) mostly silence the use of splice sites, members of the serine/arginine-rich protein family (SR proteins) and related SR-like proteins enhance it (Black 2003; Jurica and Moore 2003). In this context, SR proteins have been shown to bind a number of exonic splicing enhancers (ESEs), where they function to stimulate the splicing of adjacent introns. The splicing stimulatory action of SR proteins is presumably the result of recruitment of components of the general splicing machinery to weak splice sites and is mediated by protein interactions through their arginine/serine-rich (RS) domains. 
We have recently identified a set of multiprotein complexes, termed apoptosis- and splicing-associated protein (ASAP) complexes, with putative functions for programmed cell death and mRNA processing (Schwerk et al. 2003). ASAP complexes consist of the subunits SAP18, RNPS1, and distinct protein isoforms of Acinus. Whereas SAP18 was originally found associated with the $\operatorname{Sin} 3$ histone deacetylase complex that is involved in transcriptional repression (Zhang et al. 1997), the RNA-binding protein RNPS1 was described as a general activator of pre-mRNA processing and a regulator of alternative splicing in vivo (Mayeda et al. 1999; Sakashita et al. 2004). Several functions have been noted for the Acinus proteins, including roles during apoptotic chromatin condensation and DNA fragmentation, RNA processing, and transcriptional regulation (Sahara et al. 1999; Schwerk et al. 2003; Hu et al. 2005; Joselin et al. 2006; Vucetic et al. 2008). Consistent with a splicing function, all ASAP subunits were found to be associated with functional spliceosomes. Additionally, ASAP constitutes a subcomplex of the exon junction complex, a post-splicing complex, which is deposited 20-24 nt upstream of exonexon junctions during RNA processing and which regulates mRNA export and quality control (Rappsilber et al. 2002; Zhou et al. 2002; Jurica and Moore 2003; Tange et al. 2005; Trembley et al. 2005). Cellular localization studies have detected all ASAP subunits in nuclear splicing factor storage compartments, termed interchromatin granule clusters or nuclear speckles (Loyer et al. 1998; Mayeda et al. 1999; Schwerk et al. 2003).

Both RNPS1 and Acinus display typical hallmarks of splicing regulatory proteins like RNA-binding motifs and the presence of RS and related domains, which are known to regulate alternative splicing by modulating spliceosome assembly and splice site choice (Manley and Tacke 1996; Graveley 2000; Bourgeois et al. 2004). The importance of the RS and RS-like domains of RNPS1 during splice site selection has been described (Sakashita et al. 2004). SAP18, on the other hand, does not display structural properties of splicing factors and lacks an RS domain. In contrast, the solution structure of SAP18 reveals a ubiquitin-like $\beta$-grasp fold contained in ubiquitin and other proteins, e.g., SUMO, Elongin B (McCallum et al. 2006), with functions in various cellular processes. Often ubiquitin-like fold-containing proteins serve as cofactors in the recognition of interaction partners or the assembly of multiprotein complexes (Kiel and Serrano 2006).

To investigate the splicing regulatory potential of the ASAP subunits we have employed tethered function assays using MS2-fusion proteins and splicing reporter systems, which monitor alternative splice site selection and exon inclusion. We found, surprisingly, that SAP18 modulates splice site usage via assembly of a nuclear speckle-localized splicing regulatory protein complex containing RNPS1 and Acinus. A detailed mutational analysis demonstrated that the ubiquitin-like fold of SAP18 provides an interaction surface required for splicing modulation.

\section{RESULTS}

\section{RNPS1 and SAP18 mediate exon inclusion in an in vivo splicing assay}

To analyze potential splicing regulatory activities of individual ASAP subunits, we employed a tethered function assay, in which fusion proteins containing the RNAbinding domain of the bacteriophage coat protein MS2 and ASAP subunits were recruited to splicing regulatory sites carrying artificially inserted MS2 binding sites. Since recruitment to the RNA substrate was directed by the MS2 protein, this assay allowed us to determine ASAP effector functions independent of RNA binding. Investigating regulation of HIV-1 alternative splicing, we have previously identified a guanosine-adenosine-rich exonic splicing enhancer (GAR ESE) located in the $5^{\prime}$ part of HIV-1 exon 5 (Kammler et al. 2001). We now exchanged the GAR ESE in our previously described HIV-1 minigene (Caputi et al. 2004) by two binding sites for the MS2 protein. The generated reporter construct (SV-1-env/2MS2; depicted in Fig. 1A) contains the alternative HIV-1 internal exons 4c, a, $\mathrm{b}$, and 5, and therefore allows functional analysis of the splicing regulatory potential of selected proteins or protein domains fused to the MS2 RNA-binding domain (schematically presented in Fig. 1C). Transcripts derived from SV-1-env/2MS2 present two RNA loop structures, which are bound by the MS2-fusion proteins (Peabody 1993; van den Worm et al. 1998; Powell and Peabody 2001). Cotransfection of SV-1-env/2MS2 and plasmids coding for MS2-fusion proteins allows the analysis of the splicing regulatory activity of any protein domain by determining the splicing pattern of the reporter construct employing RT-PCR with appropriate primers. By using this splicing reporter, additionally to the mere contribution of a splicing regulatory protein domain to internal exon inclusion, its influence on even subtle differences in splice acceptor site selection can be determined. Alternative transcripts, which can be generated during the in vivo splicing reaction due to the use of any one of the set of upstream splice acceptors (A4c, A4a, A4b, and A5) and the downstream splice donor D4, are shown in Figure 1B.

As revealed by RT-PCR analysis of transiently transfected HeLa cells (Fig. 2A), neither transfection of the splicing reporter construct (lane 3) nor cotransfection of the splicing reporter and a construct expressing the MS2-fusion protein lacking any RS domain (lane 4) led to detectable levels of exon inclusion. Only processing of transcripts lacking an internal exon could be observed. In contrast, cotransfection of a control MS2-fusion protein containing the RS domain of the splicing factor SFRS7 (formerly 9G8; Manley and Krainer 2010) that was used as a positive control led, as expected, to internal exons $4 \mathrm{a}, \mathrm{c}$, and 5 inclusion (lane 5). Analysis of ASAP subunits expressed as MS2fusion proteins revealed that both full-length RNPS1 (lane 
A

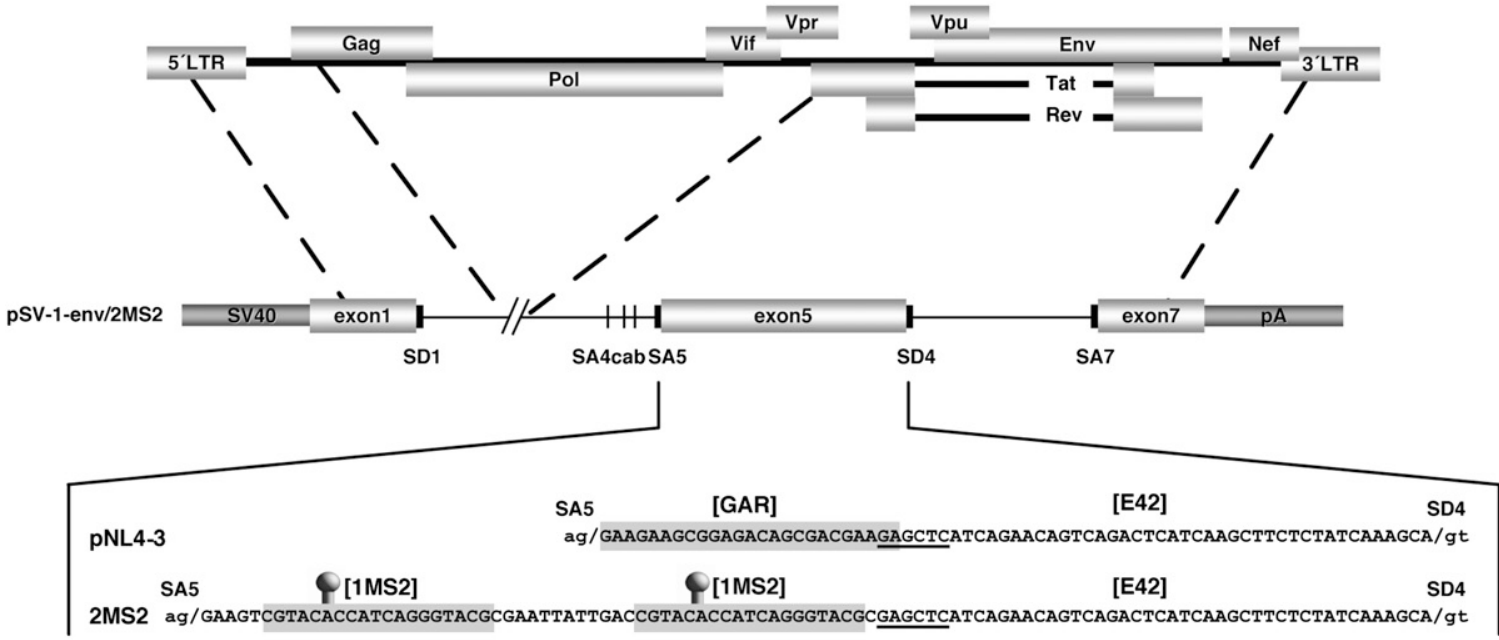

B
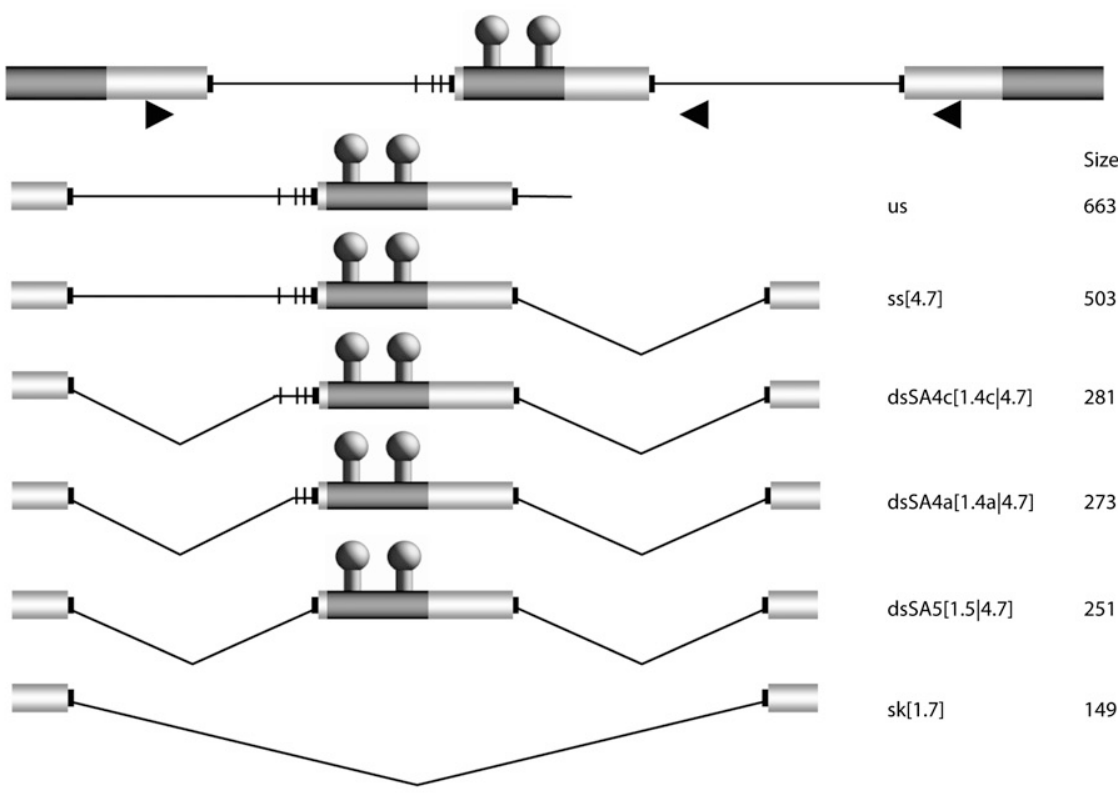

us

663

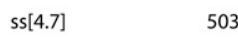

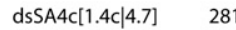

dsSA4a[1.4a|4.7] $\quad 273$

dsSA5[1.5|4.7] $\quad 251$

sk[1.7]

149

C

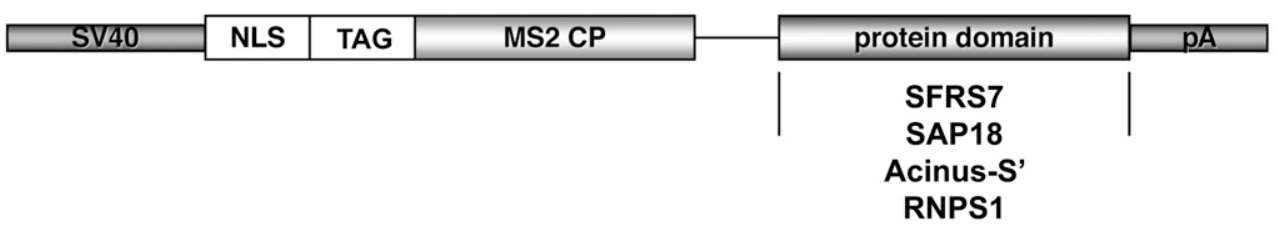

FIGURE 1. Schematic representation of the HIV-1-derived minigene SV-1-env/2MS2 and MS2-fusion proteins. (A) Top: a schematic depiction of the HIV-1 genome with open reading frames (ORFs) and long terminal repeats (LTRs) shown as gray boxes. Center: the structure of the SV1-env/2MS2 minigene. Exons are indicated as gray boxes, introns as lines. The SV40 promoter (SV40) and polyadenylation site (pA) are depicted as dark gray boxes. The position of splice acceptor (SA) and splice donor (SD) sites is indicated. Bottom: the nucleotide sequences of the GAR splicing enhancer and the two MS2 binding sites. (B) A schematic representation of the intron (lines) and exon (boxes) structure of the SV-1-env/ 2MS2 reporter and the resulting transcripts. Usage of one of the alternative splice acceptors for the doubly spliced (ds) transcripts is represented in the nomenclature (e.g., splicing from SD1 to SA5 and SD4 to SA7 is named dsSA5[1.5|4.7]). Transcript sizes are indicated at the right, primers employed for RT-PCR analyses are shown as black arrow heads. $(C)$ The structure of the MS2-fusion proteins expressed in the splicing assays. The fusion proteins comprise a nuclear localization signal (NLS), a protein-tag (TAG), and the RNA-binding domain of the MS2 bacteriophage coat protein (MS2 CP) fused to a protein domain of choice. The SV40 promoter (SV40) and polyadenylation site (pA) are indicated. 


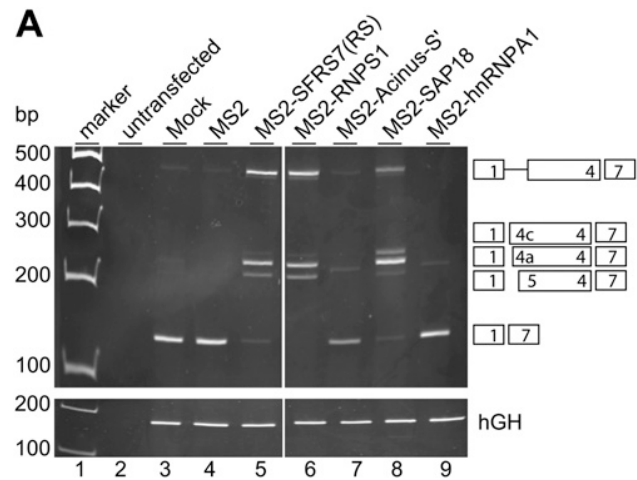

B

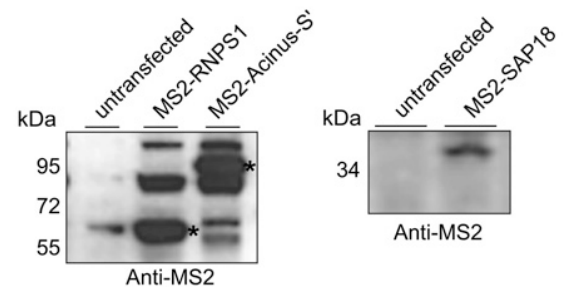

FIGURE 2. Exon inclusion activity of ASAP subunits in an HIV1-based reporter system. (A) RT-PCR assay of HeLa cells transfected with the splicing reporter SV-1-env/2MS2, the internal control pXGH5 (encoding human growth hormone, hGH) and the MS2fusion proteins indicated at the top (lanes 3-9). Untransfected control cells are shown in lane 2, marker bands in lane 1 . Spliced products (indicated schematically at the right) were analyzed with specific primers mentioned in Materials and Methods. hGH mRNA levels served as control for transfection efficiency. PCR products were separated on a nondenaturing $6 \%$ polyacrylamide gel and stained with ethidium bromide. (B) Western blot analysis of MS2-fusion proteins. Nuclear extracts of HeLa cells transfected with the indicated MS2-fusion proteins were separated by SDS-PAGE. MS2-SAP18 (right panel) as well as MS2-RNPS1 and MS2-Acinus-S' (left panel) were expressed as detected by Western blotting with an antibody against the MS2-domain. Bands corresponding to MS2-RNPS1 and MS2-Acinus-S' are labeled with an asterisk. Extracts from untransfected cells served as controls.

6) as well as, surprisingly, SAP18 (lane 8) mediated efficient internal exon inclusion. However, whereas full-length RNPS1 preferably activated the splice acceptor sites SA4a and SA5, full-length SAP18 shifted the activation toward the more distally located splice acceptors SA4c and SA4a. Importantly, expression of SAP18 lacking an MS2 binding domain did not cause significant internal exon inclusion, demonstrating that recruitment to this splicing reporter was required (data not shown). In contrast, a fusion protein consisting of the MS2 domain and full-length Acinus-S', one of the described Acinus isoforms (Sahara et al. 1999), displayed background splicing regulatory activity comparable to the background activity of the splicing silencer hnRNPA1 (cf. lanes 7 and 9). To rule out that lack of a detectable splicing regulatory activity was due to lack of proper protein expression, Western blot analysis was performed, which revealed that all ASAP subunits were expressed as MS2-fusion proteins in HeLa cells (Fig. 2B). Compared to the endogenous proteins the MS2-fusion proteins were overexpressed (Supplemental Fig. 1; cf. also with Fig. 7, see below). Splicing regulatory activity by SAP18 on the SV1-env/2MS2 reporter also required intact MS2 RNA-loop structures, since deletion of adenine at position -10 of the loops (Wu and Uhlenbeck 1987) strongly abolished internal exon inclusion mediated by MS2-SAP18 (data not shown).

\section{The ubiquitin-like fold of SAP18 is involved in splicing regulation}

Determination of the solution structure of SAP18 has revealed that SAP18 forms a ubiquitin-like $\beta$-grasp fold related to the structure of proteins like ubiquitin, SUMO, or Elongin B. This ubiquitin-like $\beta$-grasp structure comprises a mostly antiparallel five-stranded $\beta$-sheet, which is curled around a central $\alpha$-helix (McCallum et al. 2006). Since ubiquitin-like fold-containing proteins often fulfill functions of adapter proteins during the assembly of multiprotein complexes (Kiel and Serrano 2006), we investigated the requirement of the $\beta$-grasp fold structure of SAP18 for splicing regulation.

For this purpose we constructed a detailed set of SAP18 mutants and applied an enhanced MS2-tethering strategy: (1) We deleted the $\alpha$-helical region of the MS2 coat protein connecting the $\beta$-strands $F$ and $G(\Delta F G)$ and (2) we genetically fused the two subunits of the MS2 coat protein dimer, termed "single chain" (sc)-variant, facilitating its binding efficiency and assuring that each binding site is occupied by a single fused protein domain.

In a first step we gradually deleted amino acids from the C terminus of SAP18 into the ubiquitin-like fold. We additionally point-mutated selected amino acids within the $\beta$-grasp fold. Noteworthy, the amino acids aspartate at position 118 (Asp118) and threonine at position 121 (Thr121) of SAP18 are conserved in the proteins SAP18, ubiquitin, SUMO, and Elongin B and are located in the center of the ubiquitin-like fold structure (McCallum et al. 2006). We individually mutated these two amino acids into alanine (MS2-SAP18D118A, MS2-SAP18T121A) and also created the double-mutant MS2-SAP18(dm). A conserved structural feature shared by SAP18 with ubiquitin-like folds includes a positive $\Phi$ angle for lysine at position 126 (Lys126) of SAP18, which matches with asparagine at position 60 of ubiquitin (McCallum et al. 2006). We therefore also changed Lys126 of SAP18 into alanine, generating MS2-SAP18K126A.

We were finally interested in analyzing the importance of structures unique to the ubiquitin-like fold of SAP18. SAP18 contains two loop insertions between the $\beta$ strands $\beta 1$ and $\beta 2$ ( $\beta 1-\beta 2$ loop), and $\beta 3$ and $\beta 4$ ( $\beta 3-\beta 4$ loop), respectively (Fig. $3 \mathrm{~A}$ ). These loops, although spatially close to each other, are structurally poorly defined and in solution likely disordered (McCallum et al. 2006). To complete our set of mutants we constructed single deletions of 
A
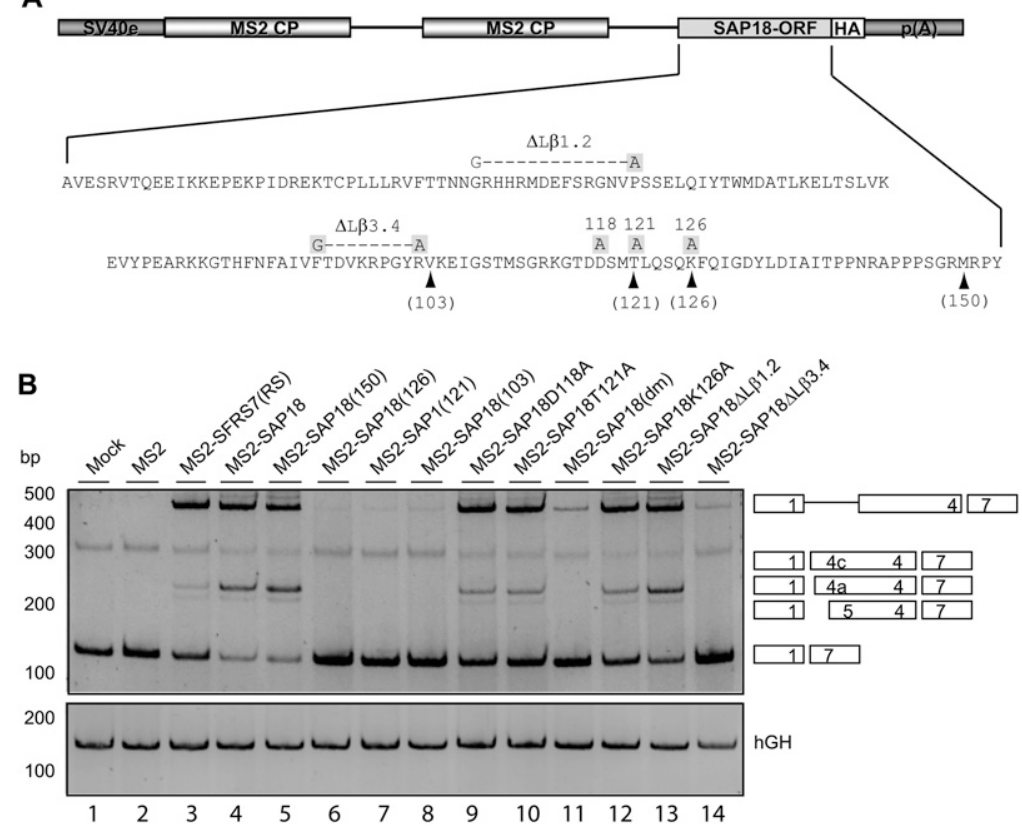

C

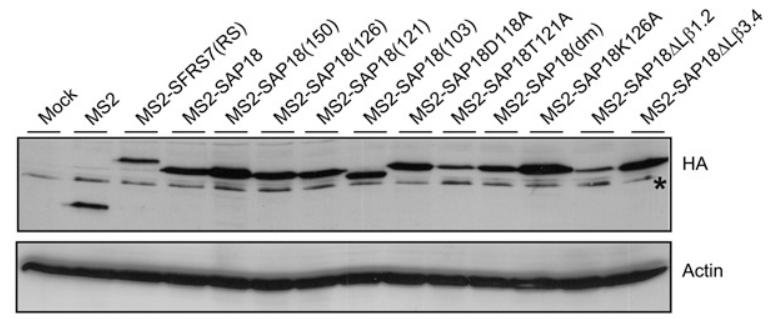

FIGURE 3. The ubiquitin-like fold structure of SAP18 is involved in exon inclusion. $(A)$ Schematic representation of the MS2-SAP18 constructs employed for analysis of the role of the ubiquitin-like fold. HA indicates the C-terminal HA-tag. Details regarding the selected mutants are given in the text. The amino acid sequence of SAP18 is shown. Amino acids changed to alanine in point mutations are highlighted in gray. The deletions of the $\beta 1-\beta 2$ and $\beta 3-\beta 4(\Delta \mathrm{L} \beta 1.2, \Delta \mathrm{L} \beta 3.4)$ loops are indicated with changed amino acids highlighted in gray. The last amino acids of the C-terminal SAP18 deletion mutants are labeled with arrow heads. (B) RT-PCR assay of HeLa cells transfected with the splicing reporter SV-1-env/2MS2, the internal control pXGH5 and the MS2-fusion proteins indicated at the top. Spliced products (indicated schematically at the right) were analyzed with specific primers mentioned in Materials and Methods. hGH mRNA levels served as control for transfection efficiency. PCR products were analyzed as described in Figure 1A. $(C)$ Western blot analysis of scNLS-MS2 $\Delta$ FG HA fusion protein expression. Nuclear extracts of HeLa cells transiently transfected with the indicated MS2-fusion constructs were separated by SDS-PAGE and protein expression was detected with an antibody against the C-terminal HA tag. An unspecific band also appearing in the Mock lane is labeled with an asterisk.

the two loops in SAP18 (MS2-SAP18DLß1.2, MS2SAP18 $\Delta \mathrm{L} \beta 3.4)$.

The impact of the SAP18 mutations on internal exon inclusion on the splicing reporter SV-1-env/2MS2 is shown in Figure 3B. Analysis of MS2-SAP18 fusion proteins with gradual deletions of amino acids from the $\mathrm{C}$ terminus of SAP18 into the ubiquitin-like fold showed that deletion of the three C-terminal amino acids had no influence on internal exon inclusion (lane 5). In contrast, further deletions into the $\beta$-grasp fold led to a complete loss of exon inclusion (lanes 6-8). Whereas single changes of Asp118 (lane 9) and Thr121 (lane 10) to alanine resulted in only a partial or no effect on exon inclusion, double mutation of both amino acids completely abolished the exon inclusion activity of SAP18 (lane 11). In contrast, point mutation of Lys126 had no effect on internal exon inclusion (lane 12). Interestingly, deletion of the two loop structures led to varying results. Whereas deletion of the $\beta 1-\beta 2$ loop had no effect (lane 13), deletion of the $\beta 3-\beta 4$ loop completely inhibited internal exon inclusion by SAP18 (lane 14). Wild-type MS2-SAP18 as well as all mutants were expressed at comparable levels in HeLa cells, as determined by Western blotting with an antibody against the C-terminal HA-tag (Fig. 3C). To obtain more quantitative data on the splicing regulatory activity of SAP18 and its mutants we employed real-time PCR analysis of the splicing experiments measuring internal exon inclusion. As can be seen in Figure 4 the extensive C-terminal deletions of SAP18, the double mutation of Asp118 and Thr121, and deletion of the $\beta 3-\beta 4$ loop diminished internal exon inclusion activities to values $<5 \%$ of those obtained with wild-type SAP18.

To specify if the splicing regulatory activity of SAP18 is a more general effect we analyzed additional reporter constructs by cotransfection with either wild-type MS2-SAP18 or with MS2SAP18 $(\mathrm{dm})$ (Supplemental Fig. 2). On a different HIV-based subgenomic splicing reporter containing two MS2-binding sites this time in exon 3, cotransfection of MS2-SAP18 caused exon inclusion activity comparable to that mediated by MS2-fusion proteins containing the RS domains of SFRS1 (formerly ASF/SF2; Manley and Krainer 2010) or SRSF7. Importantly, this effect was completely abolished by the double mutation in MS2-SAP18(dm) (Supplemental Fig. 2A). Similarly, MS2-SAP18 demonstrated splicing regulatory activity on a subgenomic $B R C A 2$ splicing reporter containing two intronic MS2-binding sites, which was strongly attenuated when MS2-SAP18(dm) was used (Supplemental Fig. 2B). Interestingly, cotransfection of a SAP18 construct influenced also moderate splicing regulation of a $B c l-X$-based splicing reporter measuring selection of either $B c l-X_{L}$ or $B c l-X_{S}$ splicing, which did not contain integrated MS2 loops, pointing to an inherent 


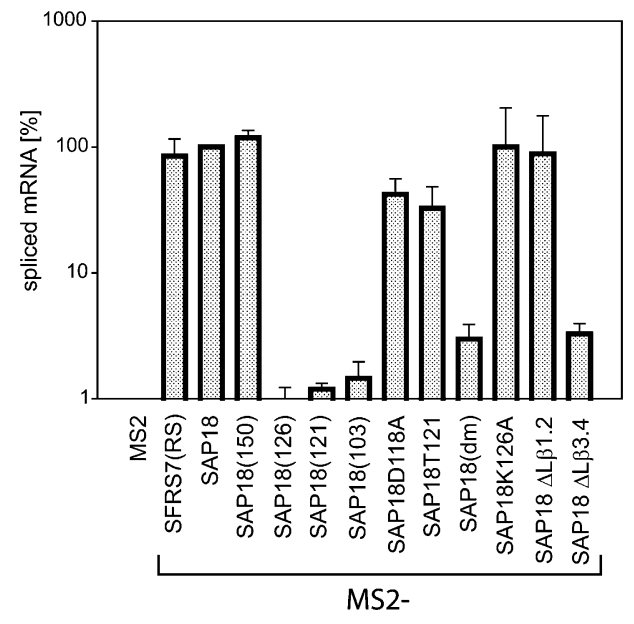

FIGURE 4. Exon inclusion activity of wild-type and mutant SAP18 measured by quantitative real-time PCR. HeLa cells were transfected with the splicing reporter SV-1-env/2MS2 and the MS2-fusion proteins indicated at the bottom. Internal exon inclusion values were determined by real-time PCR employing SYBR green and appropriate primers. The values of spliced mRNA in percent are shown in logarithmic scale, amounts obtained with wild-type SAP18 were set as $100 \%$. Mean values \pm SD obtained by three independent experiments are shown.

effect of SAP18 in this setting. Again, this effect was abolished by introducing the Asp118/Thr121 double mutation into SAP18 (Supplemental Fig. 2C), demonstrating that the splicing regulatory activity of SAP18 is not restricted to a single heterologous splicing reporter.

\section{Structural modeling of the SAP18 mutants}

To obtain more insight into the consequences of the SAP18 mutations described above, we generated homology models of the mutants based on the solved three-dimensional structure of SAP18 (using 2HDE, chain A, as template as described in Materials and Methods). As can be seen in Figure 5A, modeling of wild-type SAP18 perfectly recapitulated the described (McCallum et al. 2006) structure of the ubiquitin-like fold. Moreover, deletion of either the $\beta 1-\beta 2$ or the $\beta 3-\beta 4$ loop did not affect the structure of the $\beta$-grasp fold domain (Fig. 5B,C). The impact on the structure of SAP18 caused by the gradual deletions from the $\mathrm{C}$ terminus is shown in Figure 5D-G. Modeling of the deletion construct lacking the three C-terminal amino acids, which is functional in exon inclusion, reveals an intact $\beta$-grasp fold (Fig. 5D). In contrast, and in agreement with lack of exon inclusion activity, the structures of the SAP18 mutants with extended deletions are misfolded throughout major parts of the ubiquitin-like fold domain. However, the calculated structures of the SAP18 mutants with amino acid point mutations all indicate an intact ubiquitin-like fold (Fig. 5H-K), pointing to individual functions of the targeted amino acids during splicing regulation.

\section{Amino acid point mutations within the ubiquitin-like fold prevent nuclear speckle localization of SAP18}

It is well known that SR proteins and other splicing regulatory factors localize in nuclear compartments, termed nuclear speckles or interchromatin granule clusters (Lamond and Spector 2003; Saitoh et al. 2004). Nuclear speckle localization of SAP18 together with the ASAP subunit Acinus and the SR protein SFRS2 (formerly SC35; Manley and Krainer 2010) has been shown before (Schwerk et al. 2003). Since the mutations of Asp118 and Thr121 to alanine, which are conserved in several proteins containing a ubiquitin-like fold, abolished splicing regulation by SAP18, we analyzed whether a Flag-tagged MS2-fusion protein of SAP18 carrying the two mutations, FlagMS2-SAP18(dm), could still be found in nuclear speckles. For this purpose we transiently transfected HeLa cells with either wild-type (wt) or doublemutated (dm) FlagMS2-SAP18 and analyzed cellular localization with an antibody against the Flag-tag and antibodies specific for Acinus and SFRS2.

Immunofluorescence analyses confirmed that wild-type SAP18 was present in nuclear speckles and colocalized with Acinus (Fig. 6A, upper row) and SFRS2 (Fig. 6B, upper row). In contrast and in agreement with the results obtained in the splicing assay, colocalization of FlagMS2SAP18 $(\mathrm{dm})$ with Acinus (Fig. 6A, lower row) or SFRS2 (Fig. 6B, lower row) was largely disturbed. Acinus and
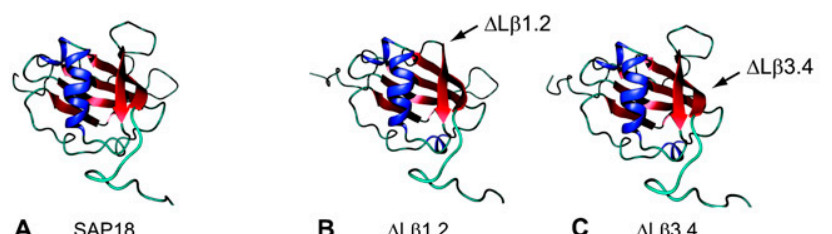

A

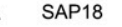$$
\text { B }
$$

$\Delta \mathrm{L} \beta 1.2$

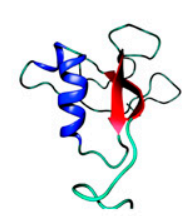

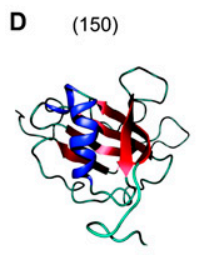

H D118A

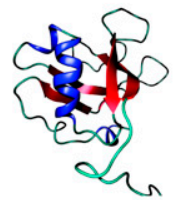

E (126)

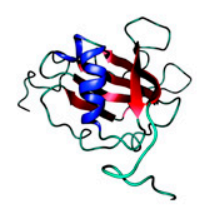

I T121A

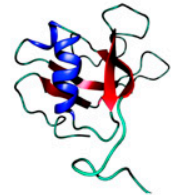

F (121)

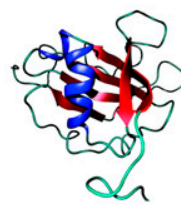

J (dm)
G (103)

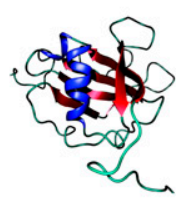

K K126A
FIGURE 5. Structural modeling of SAP18 mutants. The ubiquitinlike $\beta$-grasp structure comprises a mostly antiparallel five-stranded $\beta$-sheet (red), which is curled around a central $\alpha$-helix (blue). The top row shows structures of wild type SAP18 $(A)$ and models of the loop deletions $\Delta \mathrm{L} \beta 1.2(B)$ and $\Delta \mathrm{L} \beta 3.4(C)$. The middle row presents structures of gradual C-terminal deletions up to amino acid $150(D)$, $126(E), 121(F)$, and $103(G)$ of SAP18. In the bottom row structures of the SAP18 with the following amino acid changes are shown: D118A $(H)$, T121A $(I)$, the double mutant $(\mathrm{dm})$ containing the changes D118A and T121A $(J)$, and K126A $(K)$. 
A
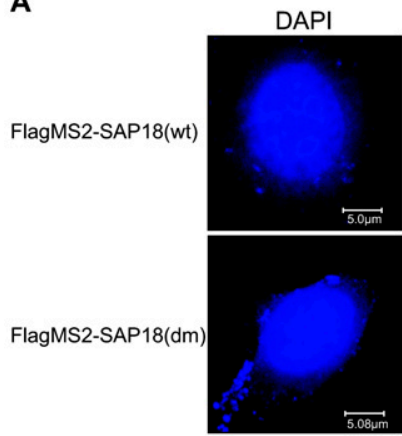

B

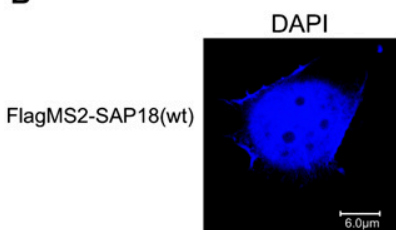

FlagMS2-SAP18(dm)
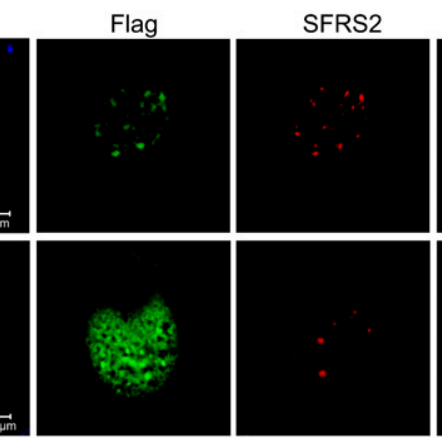

FIGURE 6. Nuclear speckle localization of SAP18 requires an intact ubiquitin-like fold structure. (A) HeLa cells were transiently transfected with a FlagMS2-SAP18(wt) and a FlagMS2-SAP18 $(\mathrm{dm})$ construct, respectively. Localization of FlagMS2-SAP18 proteins and endogenous Acinus was determined with antibodies against the Flag-tag and Acinus. Whereas FlagMS2-SAP18(wt) colocalizes with Acinus in nuclear speckles, colocalization of FlagMS2SAP18(dm) with Acinus is largely disturbed. (B) HeLa cells transfected as in $A$ were analyzed with antibodies against the Flag-tag and against the SR protein SFRS2. Only FlagMS2SAP18(wt) colocalizes with SFRS2 in nuclear speckles. Nuclei in $A$ and $B$ were stained with DAPI. Magnifications are indicated by scale bars.

SFRS2 were detected in nuclear speckles regardless of whether wild-type or mutant SAP18 was transfected.

\section{SAP18 assembles the ASAP complex via the ubiquitin-like fold}

SAP18 has been shown to interact with Acinus and RNPS1 to form the ASAP complex, which is also found as substructural component of the exon-junction complex (Schwerk et al. 2003; Tange et al. 2005). To investigate whether SAP18(dm) can still interact with RNPS1 and Acinus, we transiently transfected HeLa cells with FlagMS2-SAP18(wt) and FlagMS2-SAP18(dm), prepared nuclear extracts, immunoprecipitated the Flag-fusion proteins, and analyzed the coprecipitating proteins. As shown in Figure 7A, whereas FlagMS2-SAP18(wt) coprecipitated RNPS1 and Acinus, FlagMS2-SAP18(dm) did not bind to either RNPS1 or Acinus. The result that FlagMS2-SAP18(dm) did not interact with the other ASAP subunits RNPS1 and Acinus is in agreement with our observation that FlagMS2SAP18(dm) did not colocalize with Acinus in nuclear speckles (Fig. 6). Control immunoprecipitations performed with nuclear extracts from HeLa cells transiently transfected

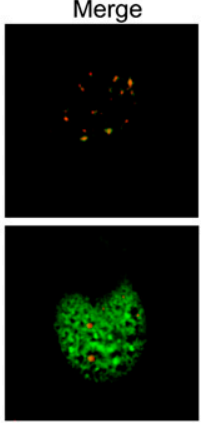

with FlagMS2-RNPS1 or FlagMS2-Acinus- $S^{\prime}$ showed that both proteins bound to their respective partners in the ASAP complex (Fig. 7B). It is noteworthy that FlagMS2-Acinus-S' precipitated significantly lower amounts of ASAP subunits than FlagMS2-RNPS1, providing an explanation for lack of internal exon inclusion following cotransfection of the MS2-Acinus-S' expression plasmid (Fig. 2A, lane 7).

\section{DISCUSSION}

Here we have analyzed the splicing regulatory activity of the subunits of the ASAP complex using several splicing reporter constructs measuring splicing modulation. Although we could not demonstrate exon inclusion activity for an isoform of Acinus (Acinus- $\mathrm{S}^{\prime}$ ), our findings support splicing regulatory functions of RNPS1 during mRNA processing (Fig. 2; Mayeda et al. 1999; Sakashita et al. 2004). Importantly, we detected here efficient exon inclusion activity for SAP18 (Fig. 2), which was surprising, since SAP18 does not contain protein motifs like RS or RS-like domains, which would account for a function during regulation of mRNA processing. In contrast, the solution structure of SAP18 reveals a ubiquitin-like $\beta$-grasp fold, a protein motif involved in protein-protein interactions and the assembly of multiprotein complexes (Kiel and Serrano 2006; McCallum et al. 2006). The presence of a ubiquitin-like fold agrees with the identification of SAP18 as a subunit associated with diverse multiprotein complexes (Zhang et al. 1997; Schwerk et al. 2003; Tange et al. 2005). Indeed, we could show here that the integrity of the structure of SAP18 is required for formation of the ASAP complex (Fig. 7).

The solution structure of the SAP18 ubiquitin-like fold highly resembles that of ubiquitin, SUMO, and Elongin B (McCallum et al. 2006). As suggested by Fairbrother and coworkers (McCallum et al. 2006), the structural relationship of SAP18 to ubiquitin and SUMO raises the intriguing question of whether SAP18 could serve as an adapter molecule to recruit a similar molecular machinery to target proteins. In this regard, it should be noted that a novel ubiquitin-like domain (termed DWNN domain) has been identified in the splicing-associated RBBP6 protein (Pugh et al. 2006). Also, in Saccharomyces cerevisiae ubiquitination of the splicing factor Prp8 regulates spliceosome dynamics, and in fission yeast loss of a ubiquitin-like 
A
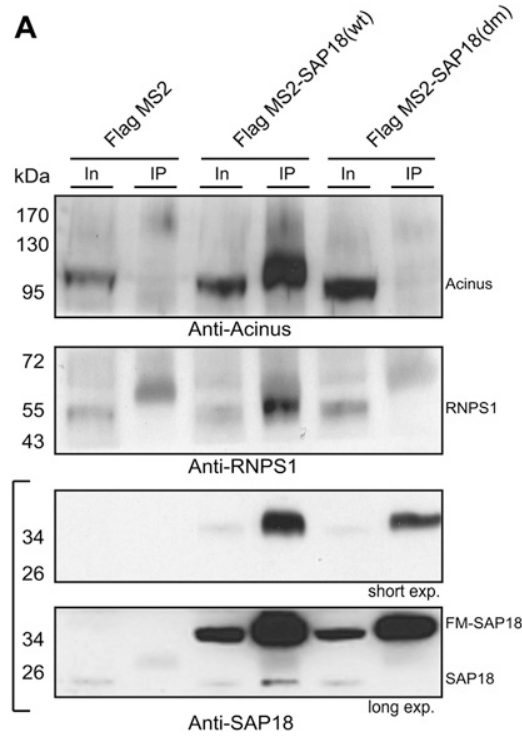

B
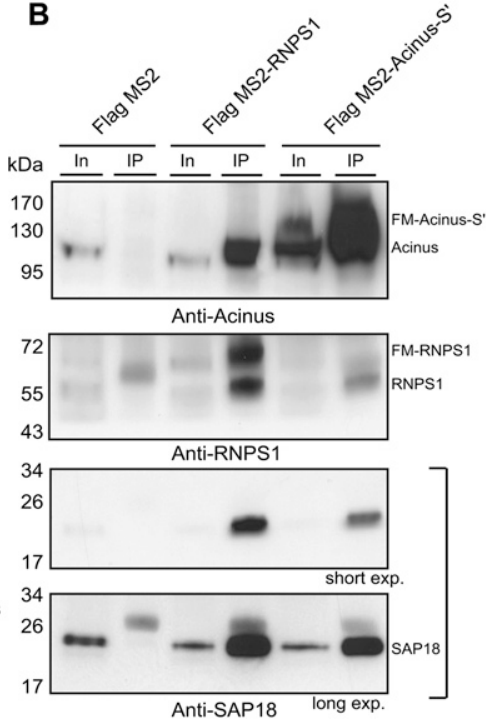

FIGURE 7. The ubiquitin-like fold structure of SAP18 is required for ASAP assembly. $(A)$ HeLa cells were transiently transfected with constructs expressing FlagMS2, FlagMS2SAP18(wt), and FlagMS2-SAP18(dm), respectively. After preparation of nuclear extracts the Flag-tagged SAP18 proteins were precipitated with a resin directed against the Flag-tag. Precipitated proteins (IP) were separated by SDS-PAGE and subsequently detected by Western blotting with antibodies against Acinus, RNPS1, and SAP18, respectively. Ten percent of the appropriate input material was loaded in the input (In) lanes. High-molecular-weight standards are indicated at the left. Only FlagMS2-SAP18(wt) containing an intact ubiquitinlike fold structure coprecipitates Acinus and RNPS1. FM, FlagMS2. (B) HeLa cells were transiently transfected with constructs expressing FlagMS2, FlagMS2-RNPS1, and FlagMS2Acinus-S', and analyzed as described in A. Although all ASAP subunits are precipitated with both Flag-tagged fusion proteins, only a fraction of FlagMS2-Acinus- $S^{\prime}$ is incorporated into ASAP. A short exposure (short exp.) and a long exposure (long exp.) of the SAP18 immunoblots are shown. FM, FlagMS2.

protein termed Hub1 results in inefficient splicing and disruption of nuclear localization of the splicing factor Snu66 (Wilkinson et al. 2004; Bellare et al. 2006, 2008). Moreover, ubiquitinated splicing factors have been detected by proteome analyses and several members of the splicing regulatory hnRNPs are modified by SUMOylation, resulting in a decreased affinity for mRNA (Peng et al. 2003; Li et al. 2004). These data provide further support for the involvement of ubiquitin-like pathways in RNA metabolism.

To prove that the integrity of the ubiquitin-like fold is required for the splicing regulatory activity of SAP18, we generated gradual amino acid deletions from the $\mathrm{C}$ terminus of SAP18 into the $\beta$-grasp fold and compared their activity in exon inclusion with three-dimensional protein structures generated from the primary amino acid sequence information and the structure of $2 \mathrm{HDE}$, chain $\mathrm{A}$, as template (Figs. 3, 4, 6). Noteworthy, all SAP18 mutants lacking significant parts of the $\beta$-grasp fold were defective in exon inclusion, strongly indicating that an intact ubiquitin-like fold structure is required for the splicing activity of SAP18. Contrary to the inactive deletion mutants, the Asp118/ Thr121 double mutant was not predicted to induce misfolding. Since this mutant however completely abrogated

internal exon inclusion, these residues are presumably directly involved in protein-protein interactions.

Deletions of $\beta 1-\beta 2$ and $\beta 3-\beta 4$ loops of SAP18 gave varying results. Although three-dimensional modeling indicated that mutation of both loops retained an intact $\beta$-grasp fold, only deletion of the $\beta 3-\beta 4$ loop impaired splicing activity. Since the $\beta 3-\beta 4$ loop is however highly charged (McCallum et al. 2006), it might provide an interface within the $\beta$-grasp fold that is required for the interaction with additional splicing components that support the regulation of mRNA processing by SAP18. In this context it is noteworthy that we observed splicing regulatory functions of SAP18 on three further reporter constructs (Supplemental Fig. 2), which were in each case abolished by introducing the Asp118/Thr121 double mutation into SAP18. A major role in this context might play the other ASAP subunits, most notably RNPS1. In support of this hypothesis is our finding that the inactive mutant SAP18(dm) did not assemble the ASAP complex as revealed by co-immunoprecipitation analyses (Fig. 7). RNPS1 has been demonstrated to mediate exon inclusion in cooperation with the SR protein SFRS11 (formerly p54 or SRp54; Sakashita et al. 2004; Manley and Krainer 2010). SFRS11 interacts with the $65-\mathrm{kDa}$ subunit of the splicing factor U2AF and promotes use of the most distal splice site on the E1A pre-mRNA. It has been suggested that the interaction with SFRS11 is required for proper nuclear speckle localization of RNPS1 (Sakashita et al. 2004). In agreement, we found that nuclear speckle localization was also abolished for the splicing regulatory inactive SAP18(dm) mutant (Fig. 6), implying that interaction with RNPS1 and other splicing factors, such as SFRS11, is also required for correct nuclear targeting of SAP18. Direct or indirect associations with RNA-binding proteins must be involved to target SAP18 to sites of RNA processing, since SAP18 itself does not contain an obvious RNA recognition motif.

Two mutually not exclusive models for the activation of internal exon inclusion by SAP18 are presented in Figure 8. In one model SAP18 could mainly function as a scaffold protein required for the stabilization of multiprotein complexes via its ubiquitin-like fold (Fig. 8A). These interactions presumably involve RNPS1 and Acinus for ASAP formation, but also additional spliceosomal components. On the other hand, SAP18 could also play a rather 

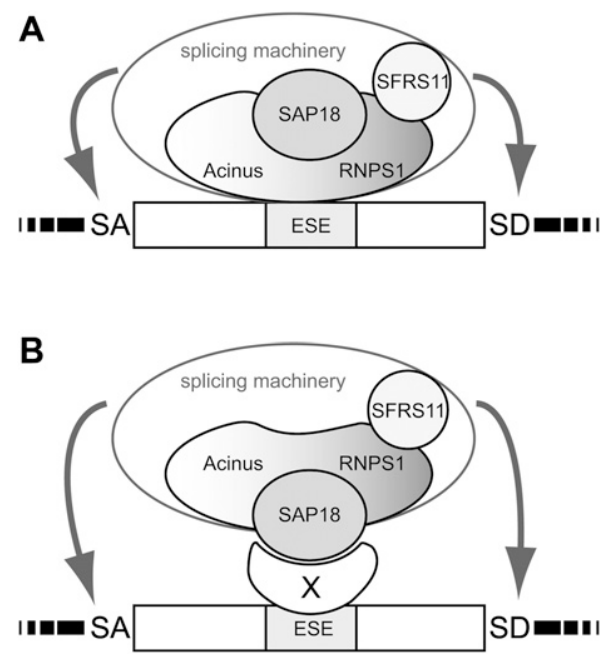

FIGURE 8. Putative models of internal exon inclusion mediated by SAP18. (A) SAP18 functions as a scaffold protein via its ubiquitin-like fold and stabilizes multiprotein complexes, including the ASAP components Acinus and RNPS1, and other splicing regulators, such as SFRS11. (B) In its function as adapter molecule SAP18 is targeted to splice sites by interaction with a hypothetical RNA-binding protein $\mathrm{X}$. Subsequently, SAP18 recruits Acinus and RNPS1 for ASAP formation via the ubiquitin-like fold. RS and RS-like domains of Acinus and RNPS1 mediate assembly of a functional splicing regulatory complex, presumably containing SFRS11. The spliceososmal complexes are targeted to the splice sites via exonic splicing enhancers (ESEs). Interactions of the splicing machinery with splice acceptor (SA) and splice donor (SD) sites lead to activation of exon inclusion.

active part during splicing regulation by functioning as an adapter molecule. In this model SAP18 is recruited to the site of RNA processing by interaction with a hypothetical RNA-binding protein X (Fig. 8B). Both models would also allow putative dominant effects of SAP18 on splicing modulation. We propose that SAP18 subsequently mediates assembly of ASAP via its ubiquitin fold. Since SAP18 does not contain typical domains for splicing regulation, presumably the RS and RS-like domains of RNPS1 and potentially Acinus function during splice site selection. It is possible that the S domain of RNPS1, which is responsible for the recruitment of SFRS11, is also involved in splicing regulation by SAP18 (Sakashita et al. 2004). Via their RS and RS-like domains RNPS1 and Acinus could mediate formation of an extended splicing regulatory competent multiprotein complex probably involving SFRS11. It has been proposed that RS domains interact with other RS domain-containing splicing factors in a phosphorylationdependent manner (Mermoud et al. 1994; Graveley 2000). Additionally, sequence-independent interactions of RS domain proteins with pre-mRNAs might play a role in spliceosome assembly (Hertel and Graveley 2005; Shen and Green 2006). Noteworthy, a tendency of RS domain proteins including Acinus for self-aggregation has been proposed (Nikolakaki et al. 2008). The extended complex is supposed to assist the basic splicing machinery in choosing appropriate splice sites for exon inclusion. This process would involve interactions with the downstream splice donor (SD) and selected upstream splice acceptor (SA) sites, similar to internal exon recognition by the bidirectional splicing enhancer we described recently (Asang et al. 2008).

Within the SV-1-env/2MS2 splicing reporter the HIV-1 exonic splicing enhancer (GAR ESE) had been replaced by two binding sites for the MS2 RNA-binding domain. Thus, our data demonstrate that a protein devoid of RS or RS-like domains can mediate internal exon inclusion at least as efficiently as the well-characterized splicing factor SFRS7, when targeted to the appropriate site on the mRNA precursor molecule. Similar results were observed on other splicing reporter constructs (Supplemental Fig. 2). Besides an RNA-binding domain this process requires a domain functional in recruiting splicing regulatory proteins. We propose that spliceosome-associated factors like SAP18 can be manipulated to influence splice site choice of target genes.

\section{MATERIALS AND METHODS}

\section{Primers}

The primers used for cloning, for site-directed mutagenesis, for deletion mutations, for sequencing of the SV-scNLS-MS2 $\Delta \mathrm{FG}$ HA constructs, and for quantitative RT-PCR are listed in the Supplemental Material.

\section{Plasmids}

HIV-1-based subgenomic splicing reporter construct SV-1-env/ 2MS2: The HIV-1 NL4/3 (GenBank Accession No. M19921) derived subgenomic reporter SV-1-env/2MS2 was constructed by substituting the GAR ESE containing EcoRI-SacI fragment of SV-1-env (Caputi et al. 2004) with two MS2 binding sites. The internal HIV-1 exon is flanked by one of the four alternative splice acceptor sites A4c, a, b, and A5 and splice donor D4.

HIV-1-based subgenomic splicing reporter construct LTR ex2 ex3 (2xMS2) SD3down: The HIV-1 NL4/3 (GenBank Accession No. M19921) derived parental plasmid LTR ex2 ex3 was cloned by insertion of a PCR product (\#1814/\#1817) into the previously described LTR 1.4tatCAT (Lenz et al. 1997) followed by substitution of the BssHII/EcoRI fragment against the 5'splice site D1 containing amplicon obtained from a PCR reaction with the primer pair \#2346/2347. 3' splice site A3 was then introduced by two PCR-amplified fragments (\#2386/2381 and \#2384/\#1766) using NdeI and XmaI restriction sites. The minigene construct contains the two small noncoding leader exon 2 and 3 and the 5 '-part of the tat exon 1, interspersed by the authentic full-length sequences for the introns 2 and 3. For insertion of the two MS2 binding sites and SD3down the AlwNI/SpeI fragment of LTR ex2 ex3 was replaced by the respective PCR product (\#2753/\#2588) containing AlwNI and SpeI restriction sites.

BRCA2-based subgenomic splicing reporter LTR BRCA2 ex22ex24-2xMS2: LTR BRCA2 ex22-ex23-SA24tatCAT was generated by a PCR reaction performed with the primers \#2145 and \#2149 using blood lymphocyte isolated genomic DNA as a template. 
Wild-typic BRCA2 sequence was confirmed by sequencing analysis. The two copies of the MS2 operator were inserted by a PCR reaction carried out with the primer pair \#2691/\#2528 and ligation of the PCR product with the XmaI/XhoI fragment of LTR BRCA2 ex22-ex23-SA24tatCAT.

$B c l$-X-based subgenomic splicing reporter construct X2.13: The $B c l$-X-based splicing reporter X2.13 was a kind gift from Dr. Benoit Chabot (Garneau et al. 2005).

Other plasmids: The plasmids pcDNA3.1-FlagMS2-SAP18, pcDNA3.1-FlagMS2-Acinus-S', and pcDNA3.1-FlagMS2-RNPS1 were kind gifts from Dr. Melissa J. Moore (Tange et al. 2005). For the construction of pcDNA3.1-FlagMS2-SAP18(dm), the fragment of the parent plasmid pcDNA3.1-FlagMS2-SAP18 was substituted with the desired mutation (D2A at position 118 and T2A at position 121) with the help of a PCR-based site-directed mutagenesis kit (Stratagene). Expression vectors for the various "single chain" MS2 $\Delta$ FG fusion proteins were generated by a PCR-based strategy using the previously described construct SV-NLS-MS2-SRSF7 as template (Caputi et al. 2004). The $\Delta$ FG mutant was constructed using XmaI and EcoRI sites and a PCRamplified fragment with deletion of the sequence encoding the flexible $\alpha$-helical loop that connects the two $\beta$-strands F and $G$ (FG loop) within the MS2 coat protein. The SV-scNLS-MS2 $\Delta$ FG plasmid with duplicated MS2 coat protein sequence (sc, "single chain") was cloned by insertion of a BglII/XhoI digested amplicon into BamHI and XhoI sites using SV-NLS-MS2 $\Delta$ FG-SRSF7 as template. For the construction of the SV-scNLS-MS2 $\Delta$ FG-SAP18 HA plasmids the BamHI-XhoI fragment of SV-scNLS-MS2 $\Delta$ FG$\Delta$ RS HA was substituted with PCR-amplified fragments using appropriate forward and reverse PCR primers containing Bam $\mathrm{HI}$ and $\mathrm{XhoI}$ restriction sites.

\section{Cell culture and transfection}

HeLa cells were maintained in RPMI 1640 (PAA Laboratories) supplemented with $10 \%$ fetal calf serum (BioWest) and $50 \mu \mathrm{g} / \mathrm{mL}$ of each penicillin and streptomycin (Invitrogen). For analysis of the splicing reporter constructs SV-1-env/2MS2, LTR ex2 ex3 (2xMS2) SD3down, and LTR BRCA2 ex22-ex24-2xMS2 cells were seeded in six-well plates and transfected using FuGENE6 reagent (Roche Molecular Biochemicals) according to the manufacturer's instructions. For reverse transcription (RT)-PCR, cells were transfected with $1 \mu \mathrm{g}$ of the reporter construct (2xMS2), $1 \mu \mathrm{g}$ of the MS2 expression plasmid and $1 \mu \mathrm{g}$ of pXGH5 encoding the human growth hormone (Selden et al. 1986) as a control for transfection efficiency. For analysis of the splicing reporter X2.13 HeLa cells $\left(2 \times 10^{5}\right.$ cells $)$ were plated in $35-\mathrm{mm}$ culture dishes and transfected using FuGENE HD transfection reagent (Roche Molecular Biochemicals) according to the manufacturer's protocol. Cells were transfected with $1.5 \mu \mathrm{g}$ of the reporter construct (X2.13), $1.5 \mu \mathrm{g}$ of plasmid expressing FlagMS2-fusion proteins, and $1 \mu \mathrm{g}$ of pXGH5 encoding the human growth hormone. Total RNA was isolated after $24 \mathrm{~h}$.

\section{RT-PCR assay}

Total cellular RNA was extracted using the RNeasy mini kit (Qiagen $\mathrm{GmbH}$ ). Analysis of cotransfections employing the splicing reporter constructs SV-1-env/2MS2, LTR ex2 ex3 (2xMS2) SD3down, and LTR BRCA2 ex22-ex24-2xMS2 was done as follows: Prior to RT, $2 \mu \mathrm{g}$ RNA samples were subjected to DNase I digestion with $10 \mathrm{U}$ of DNase I (Roche Molecular Biochemicals). DNase I was inactivated at $70^{\circ} \mathrm{C}$ for $15 \mathrm{~min}$ and the RNA samples were reverse-transcribed with 200 U Superscript III RNAse $\mathrm{H}^{-}$reverse transcriptase (Invitrogen) using $0.75 \mathrm{mM}$ oligo(dT) ${ }_{12-18}$ (Invitrogen) as primer. PCR was carried out with $1.25 \mathrm{U}$ AmpliTaq (Applied Biosystems) according to the manufacturer's protocol. Unspliced (us), single spliced intron (ss), double-spliced (ds), and skipped (sk) RNAs were detected with primers \#1544, \#1543, and \#1542. The human growth hormone (hGH) mRNA was detected with primer pair 1225-1224. PCR analyses were carried out at linear amplification range (26 cycles), allowing a semi-quantitative estimation of the transcripts produced after the splicing process. PCR products were separated on $6 \%$ nondenaturing polyacrylamide gels, stained with ethidium bromide, and visualized with the Lumi-Imager (LAS3000; Fujifilm). For analysis of cotransfections employing the splicing reporter X2.13, $1 \mu \mathrm{g}$ of RNA was reverse-transcribed with the QuantiTect Rev. Transcription kit (Qiagen) at $42^{\circ} \mathrm{C}$ for $30 \mathrm{~min}$. One-tenth of these reactions were used for PCR in a mixture containing $300 \mathrm{nM}$ primers, $1.5 \mathrm{mM} \mathrm{MgCl}_{2}, 50 \mathrm{mM} \mathrm{KCl}, 10 \mathrm{mM}$ Tris-HCl, $80 \mu \mathrm{M}$ dNTPs, and 1 unit of Taq polymerase. The PCR procedure was as follows: $95^{\circ} \mathrm{C}$ for $3 \mathrm{~min} ; 35$ cycles at $93^{\circ} \mathrm{C}$ for $15 \mathrm{sec}, 60^{\circ} \mathrm{C}$ for $30 \mathrm{sec}$, and $72^{\circ} \mathrm{C}$ for $30 \mathrm{sec}$; and a final extension at $72^{\circ} \mathrm{C}$ for $3 \mathrm{~min}$. Products were amplified using primers BX 3 and BT3 and were separated on 2.5\% agarose gels, stained with ethidium bromide. The PCR products were visualized with the ChemiDoc (Bio-Rad Laboratories). Quantitative SYBR green PCR analysis of the spliced mRNAs was obtained with primer pair \#3391 and \#3392. For normalization primers \#3387 and \#3388 were used, detecting the amount of all reporter mRNAs for each sample. Fluorescence emission was read by a LightCycler1.5 (Roche). Data are presented as the average of three independent RT-PCR experiments.

\section{Computational generation of three-dimensional structure models}

The mutated sequences of interest still show a large sequence similarity to wild-type SAP18. Hence, to predict the three-dimensional structures of the SAP18 mutants of interest, we performed homology modeling against the (known) structure of wild-type SAP18. For each SAP18 mutation, 20 homology models were generated with Modeller9v6 (Eswar et al. 2006), using chain A of the PDB entry 2HDE (McCallum et al. 2006) as template. Each homology model was scored with the Discrete Optimized Protein Energy (DOPE) (Shen and Sali 2006), and for each mutation, the homology model with minimal maximal residual DOPE was selected. Supplemental Figure 3 shows the DOPE scores for 20 homology models for the original sequence with template $2 \mathrm{HDE}$ chain A. The secondary structure was predicted with the DSSP implementation of BALL (Kohlbacher and Lenhof 2000) and visualized using BALLView (Moll et al. 2005, 2006).

\section{Antibodies}

The following primary antibodies were used for immunoprecipitation and immunofluorescence microscopy: Rabbit and mouse antibodies against the Flag-tag were obtained from Sigma and Stratagene, respectively. An antibody against RNPS1 was a generous 
gift from Dr. Akila Mayeda. A rabbit antibody against Acinus was purchased from Upstate Biotechnology and a goat antibody against SAP18 from Santa Cruz Biotechnology. For immunofluorescence microscopy Alexa Fluor 488 chicken anti-mouse IgG $(\mathrm{H}+\mathrm{L})$, Alexa Fluor 594 chicken anti-mouse IgG $(\mathrm{H}+\mathrm{L})$, Alexa Fluor 488 chicken anti-rabbit IgG $(\mathrm{H}+\mathrm{L})$, and Alexa Fluor 594 chicken anti-rabbit IgG $(\mathrm{H}+\mathrm{L})$ were obtained from Molecular Probes. For Western blot analyses anti-rabbit or anti-mouse IgG HRP conjugates were purchased from Promega and an anti-goat IgG HRP conjugate was obtained from Molecular Probes.

\section{Western blot analysis of ASAP subunits transiently transfected as FlagMS2-fusion proteins}

HeLa cells $\left(0.8 \times 10^{6}\right.$ cells $)$ were plated in $10-\mathrm{cm}$ culture dishes. Transfections were done using $1 \mu \mathrm{g}$ of plasmids expressing appropriate FlagMS2-fusion proteins (FlagMS2-SAP18, FlagMS2SAP18(dm), FlagMS2-Acinus-S', or FlagMS2-RNPS1) and $3 \mu \mathrm{L}$ of FuGENE HD transfection reagent (Roche Molecular Biochemicals). After $24 \mathrm{~h}$ cells were washed with PBS and whole cell extracts were prepared by sonification in $250 \mu \mathrm{L}$ of RIPA buffer (50 mM Tris- $\mathrm{HCl} \mathrm{pH}$ 7.4, $150 \mathrm{mM} \mathrm{NaCl}, 1 \mathrm{mM}$ PMSF, $1 \mathrm{mM}$ EDTA, $5 \mu \mathrm{g} / \mathrm{mL}$ Aprotinin, $5 \mu \mathrm{g} / \mathrm{mL}$ Leupeptin, 1\% sodium desoxycholate, $1 \%$ Triton $\mathrm{X}-100$, and $0.1 \%$ SDS). The protein content was determined with the Bio-Rad DC Protein Assay (BioRad Laboratories), and equal amounts of proteins were fractionated onto a $15 \%$ SDS-PAGE and transferred on a Hybond-C nitrocellulose membrane (Amersham Biosciences). Membranes were blocked for $1 \mathrm{~h}$ with $5 \%$ nonfat dry milk in Tris-buffered saline with $0.1 \%$ Tween 20 and then immunoblotted overnight at $4^{\circ} \mathrm{C}$ using anti-Acinus antibody at a dilution of $1: 1000$, antiRNPS1 antibody diluted 1:200, and anti-SAP18 antibody diluted 1:1000. The secondary antibodies, i.e., anti-rabbit and anti-goat, were diluted to 1:5000.

\section{Immunoprecipitations}

Immunoprecipitations were essentially performed as described (Joselin et al. 2006). $1 \times 10^{7}$ cells were transfected either with $5 \mu \mathrm{g}$ of empty vector (pcDNA3.1-FlagMS2) or with appropriate FlagMS2-fusion protein plasmids (pcDNA3.1-FlagMS2-SAP18, pcDNA3.1-FlagMS2-SAP18(dm), pcDNA3.1-FlagMS2-Acinus-S', or pcDNA3.1-FlagMS2-RNPS1). After $24 \mathrm{~h}$ cells were first washed with PBS and then resuspended in buffer A containing $10 \mathrm{mM}$ HEPES, pH 7.9, $5 \mathrm{mM} \mathrm{MgCl}_{2}, 0.25 \mathrm{M}$ sucrose, $10 \mathrm{mM}$ $\beta$-mercaptoethanol, and complete protease inhibitor mixture (Roche Molecular Biochemicals). Nonidet P-40 was added to a final concentration of $0.1 \%$ to the lysis buffer. Cells were lyzed by freezing and thawing followed by incubation on ice for $10 \mathrm{~min}$. The supernatant was collected after centrifugation in a microcentrifuge at $20,000 \mathrm{~g}$ for $5 \mathrm{~min}$ at $4^{\circ} \mathrm{C}$. The pellet was dissolved in buffer B (10 mM HEPES, pH 7.9, 25\% glycerol, $1.5 \mathrm{mM} \mathrm{MgCl}_{2}$, $0.1 \mathrm{mM}$ EDTA, $10 \mathrm{mM} \beta$-mercaptoethanol, and complete protease inhibitor mixture). $\mathrm{NaCl}$ was added to a final concentration of $400 \mathrm{mM}$ and the samples were incubated on ice for $30 \mathrm{~min}$. The samples were freeze-thawed, centrifuged at 20,000 $\mathrm{g}$ for $15 \mathrm{~min}$ at $4^{\circ} \mathrm{C}$ and the supernatants were used as input for immunoprecipitations. Twenty microliters of Flag-M2 agarose beads (Sigma) were equilibrated in buffer $\mathrm{C}(20 \mathrm{mM}$ Tris- $\mathrm{HCl}, \mathrm{pH} 7.9,0.25 \mathrm{mM}$ EDTA, $10 \%$ glycerol, $0.5 \mathrm{mM}$ DTT, and $0.2 \mathrm{mM}$ phenylmethyl- sulfonyl fluoride) containing $100 \mathrm{mM} \mathrm{KCl}$. The beads were incubated for $12 \mathrm{~h}$ with $100 \mu \mathrm{L}$ of input material at $4^{\circ} \mathrm{C}$. Following four washes with buffer $\mathrm{C}$ containing $500 \mathrm{mM} \mathrm{KCl}$, $0.5 \mathrm{mM}$ DTT, $0.2 \mathrm{mM}$ phenylmethylsulfonyl fluoride, and $0.05 \%$ Nonidet P-40, protein complexes were eluted from the beads with $2 \times$ SDS sample buffer and analyzed by SDS-PAGE and Western blotting.

\section{Immunofluorescence microscopy}

HeLa cells were grown on coverslips in a 12-well dish. Cells were transiently transfected with $1 \mu \mathrm{g}$ of each plasmid [pcDNA3.1FlagMS2-SAP18 and pcDNA3.1-FlagMS2-SAP18(dm)] using FuGENE6 reagent. Twenty hours post-transfection, cells were rinsed with PBS. Cells were fixed and permeabilized with methanol for $5 \mathrm{~min}$ at $-20^{\circ} \mathrm{C}$. After permeabilization, cells were incubated in blocking buffer (4\% bovine serum albumin, $0.05 \%$ saponin in PBS) for $1 \mathrm{~h}$. Cells were then incubated overnight at $4{ }^{\circ} \mathrm{C}$ with the primary antibodies (anti-FLAG, anti-Acinus; each 1:500) in blocking buffer. After rinsing twice with PBS, cells were incubated at room temperature for $2 \mathrm{~h}$ with secondary antibodies coupled to Alexa Flour 488 or Alexa Fluor 594 (1:1000). For nuclear staining, cells were stained with $4^{\prime}, 6^{\prime}$-diamidino-2-phenylindole dihydrochloride (DAPI, $10 \mathrm{ng} / \mathrm{mL}$ ). Cells were then mounted in mounting medium (DakoCytomation) and analyzed under a confocal laser-scanning microscope (Leica Microsystems) at a magnification of $630 \times$.

\section{SUPPLEMENTAL MATERIAL}

Supplemental material can be found at http://www.rnajournal.org.

\section{ACKNOWLEDGMENTS}

We thank Dr. Melissa J. Moore for the FlagMS2-RNPS1, FlagMS2-Acinus-S', and FlagMS2-SAP18 fusion protein plasmids and Dr. Benoit Chabot for the X2.13 reporter construct. We are grateful to Dr. Niels Gehring for the MS2-RNPS1 construct and for the antibody against MS2. We also thank Dr. David Peabody for the MS2 coat protein expression plasmid and Dr. Akila Mayeda for the antibody against RNPS1. We thank Dr. Frank Essmann for his expert assistance in microscopy. This work was funded by the Deutsche Forschungsgemeinschaft (SFB 685, SFB773 to K.S.O. and SCHA 909/2-2 to H.S.) and the Stiftung für AIDS-Forschung, Duesseldorf to H.S.

Received June 8, 2010; accepted September 16, 2010.

\section{REFERENCES}

Asang C, Hauber I, Schaal H. 2008. Insights into the selective activation of alternatively used splice acceptors by the human immunodeficiency virus type- 1 bidirectional splicing enhancer. Nucleic Acids Res 36: 1450-1463.

Bellare P, Kutach AK, Rines AK, Guthrie C, Sontheimer EJ. 2006. Ubiquitin binding by a variant Jab1/MPN domain in the essential pre-mRNA splicing factor Prp8p. RNA 12: 292-302.

Bellare P, Small EC, Huang X, Wohlschlegel JA, Staley JP, Sontheimer EJ. 2008. A role for ubiquitin in the spliceosome assembly pathway. Nat Struct Mol Biol 15: 444-451. 
Black DL. 2003. Mechanisms of alternative pre-messenger RNA splicing. Annu Rev Biochem 72: 291-336.

Bourgeois CF, Lejeune F, Stevenin J. 2004. Broad specificity of SR (serine/arginine) proteins in the regulation of alternative splicing of pre-messenger RNA. Prog Nucleic Acid Res Mol Biol 78: 37-88.

Brow DA. 2002. Allosteric cascade of spliceosome activation. Annu Rev Genet 36: 333-360.

Caputi M, Freund M, Kammler S, Asang C, Schaal H. 2004. A bidirectional SF2/ASF- and SRp40-dependent splicing enhancer regulates human immunodeficiency virus type $1 \mathrm{rev}, e n v, v p u$, and nef gene expression. J Virol 78: 6517-6526.

Eswar N, Webb B, Marti-Renom MA, Madhusudhan MS, Eramian D, Shen MY, Pieper U, Sali A. 2006. Comparative protein structure modeling using Modeller. Curr Protoc Bioinformatics Unit 5.6. doi: 10.1002/0471250953.bi0506s15

Garneau D, Revil T, Fisette JF, Chabot B. 2005. Heterogeneous nuclear ribonucleoprotein $\mathrm{F} / \mathrm{H}$ proteins modulate the alternative splicing of the apoptotic mediator Bcl-x. J Biol Chem 280: 2264122650.

Graveley BR. 2000. Sorting out the complexity of SR protein functions. RNA 6: 1197-1211.

Hertel KJ, Graveley BR. 2005. RS domains contact the pre-mRNA throughout spliceosome assembly. Trends Biochem Sci 30: 115118.

Hu Y, Yao J, Liu Z, Liu X, Fu H, Ye K. 2005. Akt phosphorylates acinus and inhibits its proteolytic cleavage, preventing chromatin condensation. EMBO J 24: 3543-3554.

Joselin AP, Schulze-Osthoff K, Schwerk C. 2006. Loss of Acinus inhibits oligonucleosomal DNA fragmentation but not chromatin condensation during apoptosis. J Biol Chem 281: 12475-12484.

Jurica MS, Moore MJ. 2003. Pre-mRNA splicing: Awash in a sea of proteins. Mol Cell 12: 5-14.

Kammler S, Leurs C, Freund M, Krummheuer J, Seidel K, Tange TO, Lund MK, Kjems J, Scheid A, Schaal H. 2001. The sequence complementarity between HIV-1 5' splice site SD4 and U1 snRNA determines the steady-state level of an unstable env pre-mRNA. RNA 7: 421-434.

Kiel C, Serrano L. 2006. The ubiquitin domain superfold: Structurebased sequence alignments and characterization of binding epitopes. J Mol Biol 355: 821-844.

Kohlbacher O, Lenhof HP. 2000. BALL—rapid software prototyping in computational molecular biology. Biochemicals Algorithms Library. Bioinformatics 16: 815-824.

Lamond AI, Spector DL. 2003. Nuclear speckles: A model for nuclear organelles. Nat Rev Mol Cell Biol 4: 605-612.

Lenz C, Scheid A, Schaal H. 1997. Exon 1 leader sequences downstream of U5 are important for efficient human immunodeficiency virus type 1 gene expression. J Virol 71: 2757-2764.

Li T, Evdokimov E, Shen RF, Chao CC, Tekle E, Wang T, Stadtman ER, Yang DC, Chock PB. 2004. Sumoylation of heterogeneous nuclear ribonucleoproteins, zinc finger proteins, and nuclear pore complex proteins: A proteomic analysis. Proc Natl Acad Sci 101: $8551-8556$.

Loyer P, Trembley JH, Lahti JM, Kidd VJ. 1998. The RNP protein, RNPS1, associates with specific isoforms of the p34cdc2-related PITSLRE protein kinase in vivo. J Cell Sci 111: 1495-1506.

Maniatis T, Tasic B. 2002. Alternative pre-mRNA splicing and proteome expansion in metazoans. Nature 418: 236-243.

Manley JL, Krainer AR. 2010. A rational nomenclature for serine/ arginine-rich protein splicing factors (SR proteins). Genes \& Dev 24: $1073-1074$.

Manley JL, Tacke R. 1996. SR proteins and splicing control. Genes \& Dev 10: $1569-1579$.

Mayeda A, Badolato J, Kobayashi R, Zhang MQ, Gardiner EM, Krainer AR. 1999. Purification and characterization of human RNPS1: A general activator of pre-mRNA splicing. EMBO $J$ 18: 4560-4570.

McCallum SA, Bazan JF, Merchant M, Yin J, Pan B, de Sauvage FJ, Fairbrother WJ. 2006. Structure of SAP18: A ubiquitin fold in histone deacetylase complex assembly. Biochemistry 45: 1197411982.

Mermoud JE, Cohen PT, Lamond AI. 1994. Regulation of mammalian spliceosome assembly by a protein phosphorylation mechanism. EMBO J 13: 5679-5688.

Moll A, Hildebrandt A, Lenhof HP, Kohlbacher O. 2005. BALLView: An object-oriented molecular visualization and modeling framework. J Comput Aided Mol Des 19: 791-800.

Moll A, Hildebrandt A, Lenhof HP, Kohlbacher O. 2006. BALLView: A tool for research and education in molecular modeling. Bioinformatics 22: 365-366.

Nikolakaki E, Drosou V, Sanidas I, Peidis P, Papamarcaki T, Iakoucheva LM, Giannakouros T. 2008. RNA association or phosphorylation of the RS domain prevents aggregation of RS domain-containing proteins. Biochim Biophys Acta 1780: 214-225.

Peabody DS. 1993. The RNA binding site of bacteriophage MS2 coat protein. EMBO J 12: 595-600.

Peng J, Schwartz D, Elias JE, Thoreen CC, Cheng D, Marsischky G, Roelofs J, Finley D, Gygi SP. 2003. A proteomics approach to understanding protein ubiquitination. Nat Biotechnol 21: 921-926.

Powell AJ, Peabody DS. 2001. Asymmetric interactions in the adenosine-binding pockets of the MS2 coat protein dimer. BMC Mol Biol 2: 6. doi: 10.1186/1471-2199-2-6.

Pugh DJ, Ab E, Faro A, Lutya PT, Hoffmann E, Rees DJ. 2006. DWNN, a novel ubiquitin-like domain, implicates RBBP6 in mRNA processing and ubiquitin-like pathways. BMC Struct Biol 6: 1. doi: 10.1186/1472-6807-6-1.

Rappsilber J, Ryder U, Lamond AI, Mann M. 2002. Large-scale proteomic analysis of the human spliceosome. Genome Res 12: $1231-1245$.

Sahara S, Aoto M, Eguchi Y, Imamoto N, Yoneda Y, Tsujimoto Y. 1999. Acinus is a caspase-3-activated protein required for apoptotic chromatin condensation. Nature 401: 168-173.

Saitoh N, Spahr CS, Patterson SD, Bubulya P, Neuwald AF, Spector DL. 2004. Proteomic analysis of interchromatin granule clusters. Mol Biol Cell 15: 3876-3890.

Sakashita E, Tatsumi S, Werner D, Endo H, Mayeda A. 2004. Human RNPS1 and its associated factors: A versatile alternative premRNA splicing regulator in vivo. Mol Cell Biol 24: 1174-1187.

Schwerk C, Schulze-Osthoff K. 2005. Regulation of apoptosis by alternative pre-mRNA splicing. Mol Cell 19: 1-13.

Schwerk C, Prasad J, Degenhardt K, Erdjument-Bromage H, White E, Tempst P, Kidd VJ, Manley JL, Lahti JM, Reinberg D. 2003. ASAP, a novel protein complex involved in RNA processing and apoptosis. Mol Cell Biol 23: 2981-2990.

Selden RF, Howie KB, Rowe ME, Goodman HM, Moore DD. 1986. Human growth hormone as a reporter gene in regulation studies employing transient gene expression. Mol Cell Biol 6: 31733179.

Shen H, Green MR. 2006. RS domains contact splicing signals and promote splicing by a common mechanism in yeast through humans. Genes \& Dev 20: 1755-1765.

Shen MY, Sali A. 2006. Statistical potential for assessment and prediction of protein structures. Protein Sci 15: 2507-2524.

Tange TO, Shibuya T, Jurica MS, Moore MJ. 2005. Biochemical analysis of the EJC reveals two new factors and a stable tetrameric protein core. RNA 11: 1869-1883.

Trembley JH, Tatsumi S, Sakashita E, Loyer P, Slaughter CA, Suzuki H, Endo H, Kidd VJ, Mayeda A. 2005. Activation of pre-mRNA splicing by human RNPS1 is regulated by CK2 phosphorylation. Mol Cell Biol 25: 1446-1457.

van den Worm SH, Stonehouse NJ, Valegard K, Murray JB, Walton C, Fridborg K, Stockley PG, Liljas L. 1998. Crystal structures of MS2 coat protein mutants in complex with wild-type RNA operator fragments. Nucleic Acids Res 26: 1345-1351.

Vucetic Z, Zhang Z, Zhao J, Wang F, Soprano KJ, Soprano DR. 2008. Acinus- $S^{\prime}$ represses retinoic acid receptor (RAR)-regulated gene expression through interaction with the B domains of RARs. Mol Cell Biol 28: 2549-2558. 
Wilkinson CR, Dittmar GA, Ohi MD, Uetz P, Jones N, Finley D. 2004. Ubiquitin-like protein Hubl is required for pre-mRNA splicing and localization of an essential splicing factor in fission yeast. Curr Biol 14: 2283-2288.

Will C, Lührmann R. 2006. Spliceosome structure and function. In The RNA world (ed. RF Gesteland et al.), Vol. 3, pp.369-400. Cold Spring Harbor Laboratory Press, Cold Spring Harbor, NY.
Wu HN, Uhlenbeck OC. 1987. Role of a bulged A residue in a specific RNA-protein interaction. Biochemistry 26: 8221-8227.

Zhang Y, Iratni R, Erdjument-Bromage H, Tempst P, Reinberg D. 1997. Histone deacetylases and SAP18, a novel polypeptide, are components of a human Sin3 complex. Cell 89: 357-364.

Zhou Z, Licklider LJ, Gygi SP, Reed R. 2002. Comprehensive proteomic analysis of the human spliceosome. Nature 419: 182185. 

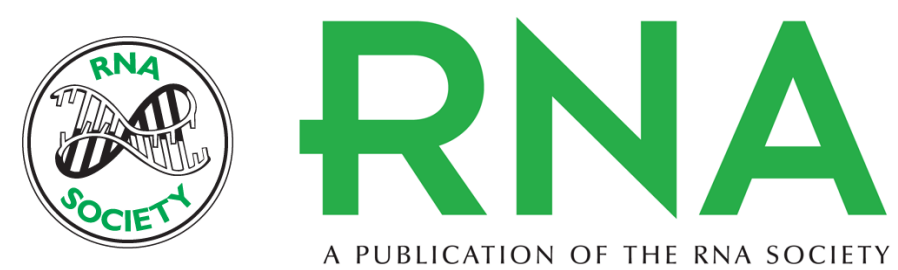

\section{Human SAP18 mediates assembly of a splicing regulatory multiprotein complex via its ubiquitin-like fold}

Kusum K. Singh, Steffen Erkelenz, Stephanie Rattay, et al.

RNA 2010 16: 2442-2454 originally published online October 21, 2010

Access the most recent version at doi:10.1261/rna.2304410

Supplemental
Material http://rnajournal.cshlp.org/content/suppl/2010/10/12/rna.2304410.DC1

References This article cites 52 articles, 20 of which can be accessed free at:

http://rnajournal.cshlp.org/content/16/12/2442.full.html\#ref-list-1

License

Email Alerting Receive free email alerts when new articles cite this article - sign up in the box at the Service top right corner of the article or click here. 